\title{
TEMPOS E ESPAÇOS DA GESTÃO UNIVERSITÁRIA: COMPREENDENDO A GESTÃO DE DEPARTAMENTOS DIDÁTICOS
}

\author{
TIEMPOS Y ESPACIOS DE LA GESTIÓN UNIVERSITARIA: COMPRENDENDO LA \\ GESTIÓN DE DEPARTAMENTOS DIDÁCTICOS
}

\author{
TIMES AND SPACES OF UNIVERSITY MANAGEMENT: UNDERSTANDING THE \\ MANAGEMENT OF DIDACTIC DEPARTMENTS
}

Andiara DEWES ${ }^{1}$

Doris Pires Vargas BOLZAN ${ }^{2}$

RESUMO: Os Departamentos Didáticos de Instituições de Ensino Superior (IES) públicas constituem-se em um âmbito institucional no qual a vida funcional dos docentes é organizada e o funcionamento dos cursos acontece por meio da manutenção da oferta de disciplinas e professores que as ministram. Nesse contexto, tivemos como objetivo compreender como acontece a gestão de Departamentos Didáticos de uma IES pública. A pesquisa desenvolvida caracteriza-se como qualitativa narrativa de cunho sociocultural. A partir das narrativas dos professores gestores (que atuavam como chefes dos Departamentos) constatamos que a gestão de um Departamento Didático é produzida através da articulação e interlocução de diversas dimensões que a compõe, estabelecendo-se como indicadores desse processo de desenvolvimento da gestão os indicadores: políticas educacionais, cultura organizacional e dinâmica curricular e atividades de ensino. Evidenciamos que são as concepções e percepções acerca dos tempos espaços da gestão que pautam os modos de atuações dos professores/gestores.

PALAVRAS-CHAVE: Gestão universitária. Departamento didático. Professores gestores.

RESUMEN: Los Departamentos Didácticos de Instituciones de Enseñanza Superior (IES) públicas se constituyen en un ámbito institucional en el cual la vida funcional de los docentes es organizada y el funcionamiento de los cursos se realiza por medio del mantenimiento de la oferta de disciplinas y profesores que las ministra. En ese contexto, tuvimos como objetivo comprender cómo ocurre la gestión de Departamentos Didácticos de una IES pública. La investigación desarrollada se caracteriza como cualitativa narrativa en una (cuño) perspectiva sociocultural. A partir de las narrativas de los profesores gestores (que (actuaban) actuaron como jefes de los Departamentos) (constatamos) fue posible verificar que la gestión de un Departamento Didáctico se produce a través de la articulación e interlocución de diversas dimensiones que la componen, estableciéndose como indicadores

\footnotetext{
${ }^{1}$ Universidade Federal de Santa Maria (UFSM), Santa Maria - RS - Brasil. Mestranda em Educação - Programa de Pós-graduação em Educação da UFSM. ORCID: <http://orcid.org/0000-0001-5920-724X>. E-mail: andiaraeduc@gmail.com

${ }^{2}$ Universidade Federal de Santa Maria (UFSM), Santa Maria - RS - Brasil. Professora Titular do Departamento de Metodologia do Ensino, Professora do Programa de Pós-graduação em Educação da UFSM e Professora do Programa de Pós-graduação em Políticas Públicas e Gestão Educacional da UFSM. ORCID: <http://orcid.org/0000-0002-1704-008X>. E-mail: dbolzan19@gmail.com
} 
de ese proceso de desarrollo de la gestión los indicadores: políticas educativas, cultura organizacional y dinámica curricular y actividades de enseñanza. Evidenciamos que son las concepciones y percepciones acerca de los tiempos espacios de la gestión que pautan los modos de actuaciones de los profesores / gestores.

PALABRAS CLAVE: Gestión universitaria. Departamento didáctico. Profesores gestores.

ABSTRACT: The Teaching Departments of Public Higher Education Institutions (IES) constitute themselves in an institutional framework, in which the operating lifetime of professors is organized and the functioning of courses takes place through the maintenance of its curricular offering and also through the professors who teach them. In this context, we aimed to understand how the management of the Didactic Departments of a public HEI occurs. The research developed is characterized as a qualitative narrative of a sociocultural nature. By analyzing the narratives of the managing professors (who acted as heads of Departments), it was possible to verify that the management of a Didactic Department is produced through the articulation and interlocution of the several dimensions that compose it, establishing the following ones as indicators of this process: educational policies, organizational culture and curricular dynamics and teaching activities. It was shown the conceptions and perceptions about the time spaces of the management that guide the modes of actions of the professors / managers.

KEYWORDS: University management. Department of education. Professors managers.

\section{Apontamentos Iniciais}

Nas duas últimas décadas as IES brasileiras têm vivenciado uma variedade de novas demandas oriundas das políticas governamentais, que resultaram em uma ampliação considerável no número de cursos, bem como de vagas de ingresso, também a diversificação do público que passa a ingressar na educação superior por meio da criação do sistema de reserva de vagas/cotas. Tal situação implica a necessidade de ampliar os serviços e suportes oferecidos pelas IES, visando o acesso e a permanência dos estudantes. Criação de novas instituições, novos campi, novos prédios, contratação de mais profissionais, tanto para o âmbito administrativo como para a docência, incentivo e investimento na oferta de cursos na modalidade a distância, integração dos ambientes virtuais de ensino-aprendizagem (AVEA) nos cursos presenciais, entre outros aspectos que decorrem do movimento expansionista e de interiorização, principalmente, no que tange às IES públicas federais. Atrelado a isso, há também o contexto sociocultural caracterizado pela cibercultura, que provoca a construção de novos modos de ser e de estar no mundo e na sociedade a partir de mecanismos e ferramentas tecnológicas. Esse novo cenário tem sido definido por pesquisadores (MOROSINI, 2016; 
BOLZAN, 2016; DEWES, 2017) desse nível de ensino como os contextos emergentes da e na educação superior.

Nessa direção, compreendemos que a gestão de uma IES é permeada por exigências e desafios de diferentes dimensões e complexidades. Pautada, principalmente, a partir de políticas e programas públicos e governamentais, consiste na proposição, organização e manutenção de tempos e espaços formativos no âmbito da educação superior.

De acordo com Tofik (2013, p. 104)

as concepções relativas às políticas educacionais têm passado por mudanças profundas nas últimas décadas, mais precisamente desde o final do século $\mathrm{XX}$ até os nossos dias. As formas de se conceituar, organizar a promover a educação formal vêm se transformando e exigindo novas respostas a antigos problemas. Com foco nas perspectivas político-institucionais, na relação docente-discente, nos ambientes e mídias e nas condições de contorno da própria comunidade em que se constitui, a instituição de ensino superior (IES) não pode e nem consegue mais permanecer no pedestal de singularidade acadêmica em que um dia se postou. Faz-se necessário conceber uma IES que venha a atender às efetivas demandas de uma sociedade global, rompendo barreiras e limitações; faz-se necessário, ainda, reinventá-la, levando-a a conquistar novos espaços e tempos, sem que perca a identidade, imprimindo-lhe um caráter de contemporaneidade.

Nessa perspectiva, os tempos e os espaços da gestão universitária precisam ser [re]pensados para que as ações e estratégias decorrentes dela não se restrinjam a atender as exigências das políticas públicas, mas que abarquem as demandas que emergem dos contextos sociais e culturais dos quais a instituição faz parte. Inclusive, visando a manutenção do seu papel na sociedade contemporânea.

Essa nova perspectiva em que se estabelece às IES implica em construir novos entendimentos acerca da gestão desse tipo de instituição, bem como do papel dos gestores. Sousa (2011, p. 97) indica que

a preocupação dos responsáveis pela gestão acadêmica durante muitos anos restringiu-se à organização dos currículos, à capacitação dos professores e ao acompanhamento rotineiro das atividades. O trabalho voltava-se aos aspectos pedagógicos, e os gestores não se envolviam nas demais questões que constituem o universo de uma instituição de educação superior, como os aspectos financeiros, de planejamento e de organização administrativa. Atualmente, os profissionais que fazem gestão acadêmica de instituições de ensino superior (IES) devem assumir novos compromissos, entre eles a responsabilidade de identificar que as práticas atuais devem atender a inúmeros desafios enfrentados pelas IES onde atuam: a necessidade de sobrevivência, de novos caminhos e de crescimento, enfrentando o aparecimento dos grandes grupos formados a partir de fusões e aquisições; a necessidade de superar as condutas e os modelos conservadores e ultrapassados de planejamento para enfrentar a grande concorrência e para 
acompanhar as exigências do mundo do trabalho; a necessidade de criar mecanismos eficientes nos programas institucionais que garantam a aprendizagem e a permanência, sobretudo dos alunos das classes C e D que chegam ao ensino superior; o acompanhamento da rápida evolução das políticas de governo voltadas a esse nível de ensino, em especial àquelas referentes à avaliação, cujas métricas têm sido consideradas como único parâmetro de qualidade.

As discussões e dilemas que tem permeado o contexto universitário, como, por exemplo, a questão do financiamento das instituições, das pesquisas que são desenvolvidas nas universidades, parcerias público-privado, entre outros, deixam, principalmente, os gestores diante de questões que, de certo modo, vão definindo os rumos que a IES vai tomando. Afinal, as decisões que são tomadas nem sempre se restringe às questões burocráticas, muitas vezes, condizem muito mais à esfera política e de concepções de educação superior e de IES pública, que são laicas e gratuitas.

Dentro do organograma institucional, os Departamentos Didáticos passam a integrar a organização das IES públicas a partir de 1968 com a chamada Reforma Universitária, promulgada pela Lei 5540/68, quando estava transcorrendo o período da ditadura militar, modificando o projeto e o formato da universidade brasileira. Cunha (2012, p. 24-25) aponta que essa reforma

alterou substancialmente a organização universitária com a implementação do modelo estrutural da departamentalização. É certo que essa perspectiva tinha a intenção de privilegiar a pesquisa básica, necessária ao projeto de desenvolvimento nacionalista dos governantes. Mas também é óbvio que o desmonte dos agrupamentos instituídos e consolidados tinha a finalidade de despolitizar a universidade e diluir as corporações tradicionalmente organizadas. Essa medida foi acompanhada da dissolução da União Nacional dos Estudantes e da desmobilização sindical em todos os níveis, que favoreceu, num contexto de vigilância e até de violência, um silenciamento das reflexões críticas, tão próprias da universidade.

O contexto social, cultural e histórico imprimiu essa nova configuração das instituições responsáveis em ofertar formação em nível superior. Não é novidade as ações e estratégias utilizadas pelos governantes, e mesmo por grupos que influenciam decisões no âmbito das autarquias públicas, visando a manutenção dos seus interesses e das suas concepções, muitas vezes, não considerando as reais demandas da maioria da população.

Cunha (2012, p. 26), ao abordar a perspectiva de desarticulação que estava incutida na criação dos Departamentos indica que

a estrutura departamental favoreceu essa perspectiva, criando grupos temáticos de investigação e centrados nessa atividade o núcleo do fazer acadêmico. Como decorrência, fracionou-se a formação dos estudantes de 
graduação, pois o Curso não mais de constituía na estrutura básica da organização do conhecimento, passando essa função para o Departamento que, como já a denominação infere, trata de uma parte do saber profissional, sem uma motivação mais forte para implementar relações horizontais com os demais saberes. Entretanto, há de ser reconhecer que a estrutura departamental foi de tal forma incorporada à cultura acadêmica que, mesmo com o advento da abertura democrática, foram poucas as iniciativas que instituíram outras formas de organização na universidade. Há uma geração de gestores e professores já formados nessa tradição, com notória dificuldade de vislumbrar outras alternativas.

Os Departamentos trazem em sua concepção resquícios da época em que foram criados, o que gera pré-conceitos quanto à sua permanência na contemporaneidade. Discussões tem acontecido em âmbito universitário questionando a manutenção desse setor dentro da estrutura de uma IES pública. Há de se considerar também que esse é hoje o espaço que congrega todo um grupo de professores, tendo eles voz e direitos iguais, sendo o chefe do Departamento um porta-voz das decisões que são tomadas pelo grupo que constitui o Colegiado Departamental. Ou seja, por mais que em determinada época a decisão de criação desse setor fora pautada em uma maneira de desarticular politicamente a classe docente, acabou se tornando, atualmente, o espaço que se caracteriza como participativo e democrático. Claro, sabemos que depende das concepções de cada gestor, que é o que vai pautar as suas ações e decisões, e da maneira como conduz os processos de gestão sob a sua incumbência. Por isso, nos sentimos instigados a investigar sobre esse lugar, conhecer as concepções dos professores gestores buscando compreender como é produzida a gestão dos Departamentos Didáticos.

Diante disso, definimos como objetivo do nosso estudo compreender como acontece a gestão de Departamentos Didáticos de uma IES pública. Entendemos que conhecer os aspectos e as dimensões que permeiam e constituem os processos de gestão de um Departamento Didático, problematizando a gestão dos e nos tempos e espaços dessa esfera em uma IES pública, torna-se relevante tanto para a construção de aportes teóricos sobre o tema, como a identificação de indicadores de qualificação e potencialização da gestão e do desenvolvimento profissional docente dos professores que atuam como gestores. Assim, os Departamentos Didáticos constituem-se como tempos e espaços administrativos e, também, formativos.

\section{Percurso investigativo}


A pesquisa desenvolvida caracteriza-se como qualitativa narrativa de cunho sociocultural. Essa compreensão está pautada nos pressupostos dos estudos de Vygotsky (1993, 2007), Bolzan (2002, 2016), Clandinin e Connelly (2011) e Freitas e Ramos (2010). Entendemos que essa abordagem fornece substrato teórico e metodológico que nos possibilita compreender como acontecem os processos de gestão e a atividade dos gestores, pois abarca os elementos e aspectos sociais e culturais construídos historicamente os quais permeiam e tecem o desenvolvimento do indivíduo, assim como o contexto. De acordo com Bolzan (2009, p. 386), uma investigação nessa perspectiva "comporta uma análise que centra sua atenção nos processos de construção coletiva, a partir da realidade sociocultural dos sujeitos participantes do processo", pois é a partir das narrativas que é possível conhecer e compreender os significados e os sentidos que permeiam e constituem a atividade do sujeito.

Desse modo, entender como a gestão acontece e como o professor produz a sua atuação como gestor implica em reconhecer a dialogicidade dos processos sociais, culturais e históricos. Segundo Vygotski (2007, p. 68), "estudar alguma coisa historicamente significa estudá-la no processo de mudança".

Para tal, como instrumento e procedimento de pesquisa utilizamos mecanismos e estratégias que nos possibilitassem identificar e compreender as articulações e as interlocuções entre o tema e os achados, assim optamos por trabalhar com entrevistas semiestruturadas construídas a partir de tópicos guia. A construção da análise foi pautada por meio da identificação das recorrências nas narrativas, possibilitando a construção de categorias e suas dimensões, partindo-se através da organização das recorrências.

Assim, como contexto tivemos quatro Departamentos Didáticos (Administração Escolar, Educação Especial, Fundamentos da Educação e Metodologia do Ensino) de um Centro de Ensino, de uma IES pública federal, do Rio Grande do Sul. Como sujeitos tivemos os professores gestores que atuavam como chefes nos referidos Departamentos, no ano de 2017.

\section{Narrativas de professores gestores: conhecendo a gestão de departamentos didáticos}

A gestão constitui-se por meio de processos que implicam em ações e estratégias que visam a manutenção de tempos e espaços formativos. Manutenção esta que abarca elementos do âmbito de estrutura física e de pessoal, atendendo demandas que condizem à organização já existente como às novas propostas, como, por exemplo, a manutenção de número de docentes necessários para atender as disciplinas já integrantes das matrizes curriculares dos 
cursos, a contratação de novos docentes quando da criação de novos cursos, novas disciplinas, aumento de vagas de ingresso que resultam no aumento de estudantes de turmas.

Essas são questões que fazem parte do cotidiano da gestão de Departamentos Didáticos. No âmbito da IES pesquisada, as atribuições e as competências dos Departamentos e das chefias destes são normatizadas pelo Regime Geral da Instituição (UFSM, 2011, p. 2627), especificamente no Art. 80 é expresso que compete ao Departamento Didático:

I - elaborar seu plano anual de atividades e a parte que lhe competir no Plano de Desenvolvimento Institucional - PDI, da Universidade; II - atribuir encargos de ensino, pesquisa e extensão ao pessoal docente que o integra; III - coordenar o trabalho do pessoal docente, visando ao atendimento das demandas dos cursos de graduação e pós-graduação; IV - tomar as providências de ordem didática, científica e administrativa que julgar necessárias ao bom andamento dos trabalhos; V - elaborar a lista de oferta de disciplina do departamento; VI - estimular o constante aperfeiçoamento de seus servidores; VII - propor ao colegiado a admissão de pessoal docente, observadas as disposições estatutárias e regimentais; VIII - propor ao colegiado de curso alterações nas ementas disciplinares bem como as cargas horárias das disciplinas lotadas no departamento; IX - ministrar o ensino das disciplinas que lhe forem pertinentes, sempre que solicitado pelos cursos, de acordo com os recursos humanos e materiais disponíveis e com o projeto pedagógico do respectivo curso; e X - providenciar a tramitação de convênios com entidades que ofereçam campo de aplicação às atividades do departamento, após a aprovação do colegiado de departamento.

O atendimento de cada atribuição não está restrito apenas às questões essenciais daquela demanda, pois outros aspectos acabam permeando cada decisão, cada ação a ser proposta e efetivada. Por exemplo, a contratação de novos professores está implicada na necessidade de haver vagas, na possibilidade de contratação por regime de trabalho efetivo ou temporário, a decisão pela área em que será realizado o concurso ou a seleção, entre outras questões. Desse modo, a gestão de um Departamento Didático é composta por diversas dimensões, que ao mesmo tempo em que se distinguem entre si se articulam, resultando em um processo dinâmico em que se permeiam e entrecruzam produzindo o processo de desenvolvimento da gestão.

Nas narrativas que seguem, os professores gestores expressam as suas concepções acerca do papel do Departamento Didático:

O departamento é para racionalizar tempos, racionalizar decisões, processos de tomadas decisórias, mas eu não sou ingênua, ele foi criado no regime militar para separar as pessoas para não ter a visão do coletivo do participativo. Ele faz parte de todo uma linha fordista de pequenas etapas de fragmentação do trabalho. Só que nós como somos uma visão humanista eu acho que o Centro de Educação é o mais democrático no sentido de fato fazer valer as normas do grupo. $O$ que que eu percebo, em outros Centros 
eu ouço assim que não sai reunião de Departamento, em vários locais dizem que não fazem. [...]. Fica uma gestão autoritária, centralizadora na pessoa, o contrário da nossa que tudo é democrático, tudo é no coletivo, nós não deliberamos nem uma vaga para qual disciplina vai sem contar os dados e colocar na mesa e ver qual é a necessidade de fato, com transparência de verdade. (Professor gestor 01).

Como nós trabalhamos com estágios supervisionados, com práticas de ensino, nós temos que provar para o nosso instituído, como professor do Departamento de Metodologia do Ensino, que a natureza do nosso trabalho é diferente de outros Departamentos. Então o que acontece? Temos feito, principalmente, o ano de 2016 para cá, nós temos feito muita discussão como, por exemplo, uma escala superior a administração que é a Próreitora de Graduação para fazer uma discussão e fazer valer o nosso conhecimento sobre a nossa ação. Então na verdade nós estamos propondo políticas dentro da Universidade enquanto Departamento enquanto pessoas que trabalham com uma especificidade que é estágio supervisionado em educação. (Professor gestor 02).

Ele tem um papel importante no sentido que a sua principal atribuição como Departamento é o cumprimento das necessidades dos cursos em atender professores. O curso tal tem tais disciplinas ele tem que evitar que fique faltando professor, colocar pessoas. Eu nesses 18 anos eu acho que quase todos foram contemplados com professores no meu Departamento, todos a gente coloca procura, às vezes, leva uma semana, duas semanas, porque contratar um substituto não é fácil, mas dou todo o acompanhamento para o pessoal novo que está chegando, para o substituto o que tem que ser feito, então, é essa a minha atribuição de fazer o Departamento funcionar. Tem que fazer isso, atender, ele é um assessor às coordenações, coisas que as coordenações não entendem, o assessoramento, entendem como subordinação do Departamento. (Professor gestor 03).

O papel dele é na organização dos professores, principalmente, em função das disciplinas, em função da vida do professor. Então o Departamento é o lócus do professor, sua vida funcional e de sua vida acadêmica. A acadêmica de progressão do professor no sentido de ele ter o espaço para ele se capacitar [...], é a distribuição das tarefas do professor no Departamento. (Professor gestor 04).

Evidenciamos nas falas dos professores gestores que o entendimento que eles possuem sobre o papel do Departamento pauta a sua atuação como gestor desse lugar. O professor gestor 01 aborda a criação dos Departamentos nas IES, como vimos anteriormente, e como, na percepção dele a dinâmica de funcionamento seja distinta da época em que foram criados e das intenções e pressupostos que se tinha. Esse conhecimento histórico lhe dá subsídio para definir e argumentar acerca da sua maneira de conduzir os trabalhos no âmbito da gestão do Departamento. Essa perspectiva também é constatada na fala do professor gestor 02, quando ele indica entender que é função do Departamento ser propositor no âmbito institucional de políticas de organização interna e para tal, ter como suporte os conhecimentos específicos de cada área do conhecimento. Assim, o Departamento estabelece-se como fonte de consulta 
para a administração central, afinal os conhecimentos pertinentes à cada área, em sua maioria, estão agrupados nos Departamentos.

Nessa direção, os profissionais que constituem a força de trabalho de uma IES, especialmente, os que ocupam cargos de gestão tem um papel importante dentro da instituição para além das questões burocráticas. Colombo (2010, p. 169), salienta que são os profissionais que atuam nas instituições de ensino que "com suas habilidades e competências diferenciadas, são os responsáveis não somente por implantar os planos emanados pela alta administração, mas também por apontar e ajudar a construir estratégias emergentes”.

Os professores gestores expressam em suas falas as suas percepções e concepções, diante de uma perspectiva geral do Departamento e das suas dimensões de atuação, qual o papel do gestor e os elementos que permeiam a sua atuação:

De mediar esses conflitos, de obedecer às normas instituídas, fazer valer nas reuniões as normas do colegiado, as normas o próprio Regimento do Centro e dar prosseguimento a toda a vida dos professores desde assim, por exemplo, qualificação profissional, afastamento de professores, diárias e passagens, tudo é deliberado no coletivo, não decido nada, nada, nada sozinha. A minha gestão é participativa é democrática e eu faço questão de tudo aquilo que eu estudo lá na gestão colocar em prática na dinâmica do dia a dia. (Professor gestor 01).

Então na minha concepção um bom gestor ele tem que saber administrar a questão orçamentária, a questão do colegiado do Departamento, a gestão de pessoas que nós trabalhamos no Departamento nós trabalhamos com quase, em média, 50 professores e mais três técnicos administrativos, então trabalha basicamente com 53 pessoas. Então trabalha com a gestão de pessoas que é a questão das relações de trabalho e, mas também tem as relações de afetividade que eu acho que tem que estar contido dentro do processo de mediação, porque o gestor é um mediador das políticas públicas que temos que discutir, temos que implementar, temos que propor dentro da universidade e tu vais propor com os teus pares. (Professor gestor 02).

Eu acho que no momento o Departamento ele tem a finalidade de gerenciar ou assim é o local de gestão dos professores, o Departamento na chefia do Departamento, o chefe tem que estar preocupado em saber se seus professores estão tendo essa facilidade ou então se eles estão tendo formação para isso, de que forma eles estão conseguindo ter acesso a esse conhecimento, eu acho isso fundamental. [...]. Dar suporte para os professores para que eles possam discutir sobre essas questões. Como Departamento se é onde o professor está locado, eu acho que sim que o Departamento tem ou deveria ter essa preocupação e ter esse espaço também de discussão sobre as cotas, sobre as novas tecnologias que estão entrando nos espaços pedagógicos, [...], porque no mundo contemporâneo eu acho que a gente não tem espaço para dizer assim "eu não vou fazer porque eu não sei". Eu acho que a gente precisa pensar assim: "bom, como que eu posso me organizar? Porque eu preciso ter esse novo conhecimento". (Professor gestor 04). 
Nessas narrativas constatamos que os professores têm noção da amplitude das dimensões que permeiam e constituem, tanto a sua atuação como gestores como da função do próprio Departamento, na organização e manutenção da estrutura universitária. Isso por meio do reconhecimento dos distintos aspectos que compõem as exigências que precisam ser atendidas, dentro dos prazos estipulados em nível institucional, abarcando o âmbito das dinâmicas curriculares e das atividades de ensino, o âmbito da cultura organizacional e o das políticas públicas. Essas dimensões vão se articulando e sendo colocadas em interlocução, à medida que vão permeando o cotidiano dos Departamentos, nas exigências e nos desafios que emergem e que precisam ser atendidos, tanto pelo Departamento como pelo grupo de docentes vinculados a este, como pelo gestor desse local que gerencia as atividades e ações no âmbito departamental.

Nas duas narrativas que seguem, os professores gestores relatam situações que vivenciam em que há um tensionamento entre as normativas e as demandas institucionais e as demandas e especificidades da gestão de pessoas, no caso dos Departamentos, a gestão da vida funcional dos docentes que estão lotados naquele setor:

Negócio de licença saúde do professor que não vinha os laudos, tinha que abrir concurso para substituto, ter que estar ligando, estar pedindo por favor, então essa questão assim são as coisas mais delicadas. Que tu pensas assim ninguém pediu para ficar doente, está frágil, mas ao mesmo tempo a instituição precisa funcionar se não vem o Ministério Público te cobra que os alunos estão sem aula e tu assim tens que engolir cobras e lagartos e ter que ligar e dizer "por favor, estamos precisando do laudo sem ele não dá para abrir o processo". Esse para mim foi o desafio mais doloroso em vários momentos, [...]. Tinha que ligar pedindo "por favor, leva rápido lá senão nós vamos perder o substituto", às vezes, era questão de dias [...]. Então isso é uma coisa que tu tens que aprender a respeitar o tempo espaço do enfermo. E como gestora pública tu tens que pensar na instituição, nos alunos, na outra ponta. Então fazer essa mediação para mim foi a coisa mais dolorosa da vida. [...], que estava como a gestora, tu estás entendendo? Mas que eu tinha que fazer cumprir a lei, tinha que agilizar, $e$ muitas vezes eu ia para casa e chorava, chorava, chorava que dizia "Meu Deus! Será que eu vou ter que ir lá na casa deles? Será que eu vou ir atrás?", ai eu pensava, mas isso não infringir? Não é assédio moral? [...]. Equilíbrio. [...]. Fazia a parte burocrática funcionar, mas sem desumanizar. Sem tu pisar, sabe, no outro que está sofrendo. (Professor gestor 01).

Eu tenho uma preocupação no Departamento assim desse lado pedagógico tem uma preocupação também no sentido do cuidado com o professor, em termos assim, uma das coisas que eu sempre faço é o incentivo ao professor de participar de atividades além do que ele faz na sala de aula, de participar de capacitação, de participar de eventos, então assim, seja ele professor efetivo ou substituto, e ontem nós tivemos um choque porque até então foi uma coisa que eu nem percebi, porque foi a primeira situação que me apareceu como chefe de Departamento, uma professora substituta que com 
um trabalho aprovado em um evento em Pelotas, não conseguia fazer o afastamento dela então ligamos para a PROGEP, e fiquei sabendo ontem, porque foi a primeira vez que surgiu isso, que o professor substituto não pode sair afastado para apresentar trabalho. Ele pode sair para dar palestra, ele pode sair para dar curso e entre parêntese está: exceto apresentar trabalho. Poxa! Ela com o trabalho aprovado e tudo, sabe, então isso é uma coisa que me incomodou também, sabe, porque é uma professora que faz muito, bem organizada como todos os professores, enfim, mas assim é uma pessoa que faz todo seu trabalho de professora, tinha organizado tudo já para se afastar nesses dias, que não eram muitos, e é impedida de apresentar um trabalho que foi aprovado em um evento internacional. Então isso são coisas assim a gente vai aprendendo com isso, então aí, sabe, então são coisas que muitas vezes a gente esbarra, quer dizer, eu dou todo o incentivo para os professores, independente porque eu acho que o professor substituto e professor efetivo não faz diferença nenhuma. (Professor gestor 04).

Constatamos nessas falas alguns dos desafios que os professores gestores enfrentam no âmbito da gestão. $\mathrm{O}$ embate entre as normatizações e as demandas pessoais emergem no âmbito da gestão de pessoas. O professor gestor se encontra na situação de colega dos professores e de chefe, e, como se evidencia nas narrativas, essa situação pode colocar o gestor diante de situações delicadas e complexas.

Abordando a conjuntura em que os gestores se encontram e, especialmente, no âmbito de instituições públicas, Bergue (2014, p. 81) problematiza:

\begin{abstract}
como o pensamento sistêmico pode aperfeiçoar a gestão de pessoas nas organizações do setor público? As organizações são sistemas abertos, constituídas de subsistemas, e inseridas em um ambiente, com o qual interagem, influenciando e sendo por ele influenciadas. Esse ambiente, por sua vez, é um espaço complexo em que opera um significativo número de variáveis (exógenas), que afetam direta ou indiretamente, em diferentes níveis de intensidade, a dinâmica da organização e em particular a sua dimensão humana. Pensar estrategicamente a gestão de pessoas implica reconhecer que esse contexto de inserção da organização não somente tem as pessoas como vetores de troca de energia, mas é uma produção de significado socialmente construído e compartilhado por essas mesmas pessoas.
\end{abstract}

Também no âmbito da gestão de pessoas está atrelada, no caso dos Departamentos, a organização dos encargos didáticos e dos quadros de horários dos docentes, refletindo na organização do trabalho dos docentes. Nessa direção, a narrativa do professor gestor 03 evidencia a maneira como ele organiza a distribuição dos encargos e dos horários de aula:

E aqui no Departamento eu faço uma planilha, distribuo para todos a proposta. [...]. Tu dás aula segunda e terça, portanto tu não podes ter turma nesse horário. Primeiro é Graduação e depois a Pós-graduação, essa é uma outra luta que se tem no Departamento que os professores, [...]. "Ah, eu não quero dar aula só quero dar na Pós-graduação”, aí eu pergunto, pergunta 
básica: "o concurso que tu fizeste para a universidade é para que área? É para Pós-graduação? Ok. Está livre”. "Ah, porque em universidade tal...", "então, peça transferência para lá". Aqui no mínimo uma disciplina na Graduação tu vais dar aqui, no mínimo 8 horas no somatório. E distribuo abertamente. Têm professores que preferem trabalhar à noite, [...]. têm outros professores que gostam de trabalhar pela manhã, tem professor que gosta à tarde e tem gente que não gosta de trabalhar à noite, então por que eu vou te colocar para trabalhar de noite se tu não gostas e se eu gosto de trabalhar à noite? É uma questão de bom senso. [...]. Mas eu trabalho com praticamente todos os cursos de licenciatura por causa da disciplina que é obrigatória em todos os cursos que formam professores. Então, a gente faz uma rotatividade, mudando de curso para não ficar muito viciado com aquela turma, aquele curso, a maneira, o comportamento, atitude, visão dos alunos que eles têm voltado somente para uma área específica, para nós é importante falar em políticas públicas transitar em outras áreas do conhecimento. (Professor gestor 03).

Por meio desse relato constatamos que nesse Departamento o gestor dinamiza, de certo modo, um equilíbrio entre os horários das atividades de modo que haja o rodízio e sejam atendidas preferências dos professores, quanto ao horário e ao curso/área de atuação. Desse modo, evidencia-se que esse elemento que compõem a dimensão da dinâmica curricular e das atividades de ensino, que é ofertar professores para as disciplinas e organizar os respectivos horários, é permeado pela dimensão da cultura organizacional, pois traz aspectos da gestão de pessoas, da dinâmica institucional e organizacional e, de certo modo, também das relações interpessoais. Considerando a quantidade de disciplinas e de professores, essa organização configura-se em um desafio para o professor gestor, pois, de um lado, tem as exigências institucionais e, de outro, há os interesses dos docentes. Portanto, a falta de harmonia e equilíbrio nesse processo de organização pode resultar em tensionamentos.

Essa conjuntura torna fundamental que todos compreendam a gestão universitária, as exigências e os desafios que a permeiam e assim vão constituindo os processos de gestão, tanto no âmbito dos Departamentos como da instituição. Ou seja, que os professores, assim como os que estão atuando como gestores, entendam os elementos que permeiam e constituem a gestão e, principalmente, compreendam qual o papel da gestão no cotidiano de uma IES pública, bem como qual o seu papel como integrante desse contexto.

Tofki (2013, p. 115) chama a atenção que,

refletir sobre a gestão acadêmica é instigante, pois, de um lado, deve atender ao processo de regulação e supervisão do Ministério da Educação, que estabelece indicadores de qualidade do ensino superior, e, por outro, deve alcançar os resultados organizacionais estabelecidos [...]. A perspectiva é a de que as IES construam uma gestão acadêmica compartilhada, sem perder de vista a totalidade das relações internas no contexto das instituições como 
também as relações externas sociais, políticas e econômicas que se apresentam na sociedade.

Estabelece-se, assim, o tensionamento entre as demandas externas e internas. Discutir e analisar as demandas que emergem do e no contexto universitário, sejam elas oriundas do contexto social e cultural ou de dentro da própria instituição, é fundamental para que se consolide a gestão como propositora de políticas, ampliando a sua visão e o campo de atuação, ultrapassando a atuação restrita ao viés administrativo e burocrático.

Nessa direção, os professores gestores 02 e 03 narram, a partir de suas vivências como gestores, percepções acerca das influências externas com o âmbito da gestão:

O Departamento assim ele lida com professor. Claro que a gente vai também com as coordenações de curso a gente trabalha com a dimensão da gestão dos cursos. Mas nós lidamos com gestão de pessoas, certo, então sendo o Departamento uma célula de debate, de discussão, aonde está o sujeito real que vai para sala de aula para trabalhar com esses novos contextos lá dos novos contextos vem temas e debates para o Departamento. Só para tu teres uma ideia, na última reunião do colegiado do Departamento ficou definido que na próxima reunião ordinária nós teremos pauta única: vamos discutir as reformas que estão sendo propostas da educação brasileira. E isso já discutíamos questões no Departamento, por exemplo, quando se criou aquelas disciplinas sobre inclusão, afrodescendente, o Departamento debate isso. Por que? Porque o sujeito que vai para a sala de aula para trabalhar com esses novos contextos é o sujeito que está no Departamento e é dali que nós vamos começar a discussão para fazer o enfrentamento, que é o meu colega e eu, é nós que vamos para a sala de aula para viver essa nova realidade. (Professor gestor 02).

Em termos de cotas o Departamento não tem nenhuma interferência, não sofre nenhuma interferência em nada. Na questão da EaD também no Departamento não houve nenhuma interferência porque os professores que estão trabalhando na EaD são convidados e aqueles encargos, esse semestre agora que começaram a contar uma hora por polo, que dá aula, mas esse há um, eu não diria um acordo, mas um entendimento de que como ele recebe uma bolsa e ela é legal, diga-se de passagem, eles não são computadas na hora de distribuir a disciplinas entre o Departamento, então essa questão não tem afetado. (Professor gestor 03).

Evidenciamos que que são distintas as percepções dos professores gestores sobre como as influências externas repercutem no ambiente universitário na própria gestão de uma IES. As concepções e percepções subsidiam a atuação dos gestores, logo, se e como uma demanda será discutida e analisada no âmbito do Departamento, depende de como o gestor vai conduzir essa discussão. Uma abordagem visando otimizar e qualificar o trabalho docente perpassa pela oferta de tempos e espaços em que o docente possa compartilhar, discutir e 
pensar com o grupo como atentar as exigências e os desafios do seu trabalho como professor formador, atuando no ensino, na pesquisa e na extensão.

Nesse sentido, esse entendimento é evidenciado na fala que segue:

A minha função ali na chefia do Departamento não é só para assinar memorando, é para também questionar o instituído, contribuir para políticas que avancem a própria universidade, defender a universidade pública, isso também é uma coisa muito importante hoje, sempre foi e cada vez continua mais você tem um cargo de representatividade você tem uma representação diante da tua comunidade, ou seja, tu tem credibilidade para fazer essa discussão em todos os âmbitos possíveis, inclusive, sempre naquela ótica de defender a universidade pública, gratuita, de qualidade, com condições de trabalho. (Professor gestor 02).

Compreender o papel do Departamento no contexto de uma IES pública implica em reconhecer as dimensões que o compõem, logo os aspectos que precisam ser abarcados no desenvolvimento da gestão desse lugar. As divergências que surgem precisam ser vistas como possibilidades de [re]pensar o papel desse setor, bem como o da instituição e dos próprios processos formativos que são dinamizados na universidade. Afinal, a universidade tem como objetivo principal a formação de novos profissionais por meio de processos de ensino e de aprendizagem de excelência, resultando, inclusive, na produção de novos conhecimentos. Diante disso, torna-se essencial gestores comprometidos tanto com a manutenção da instituição, como com os dos tempos e espaços formativos em consonância com os contextos sociais e culturais.

\section{Apontamentos conclusivos}

Esboçando um panorama geral a partir das narrativas dos professores gestores, compreendemos que a gestão de um Departamento Didático vai sendo construída/produzida por meio da articulação e interlocução entre as diversas dimensões que a compõe. Como indicadores desse processo de desenvolvimento da gestão temos o indicador das políticas educacionais, o da cultura organizacional e o da dinâmica curricular e atividades de ensino. Na figura 1 representamos esse movimento da gestão:

Figura 1: Dimensões da gestão do Departamento Didático. 


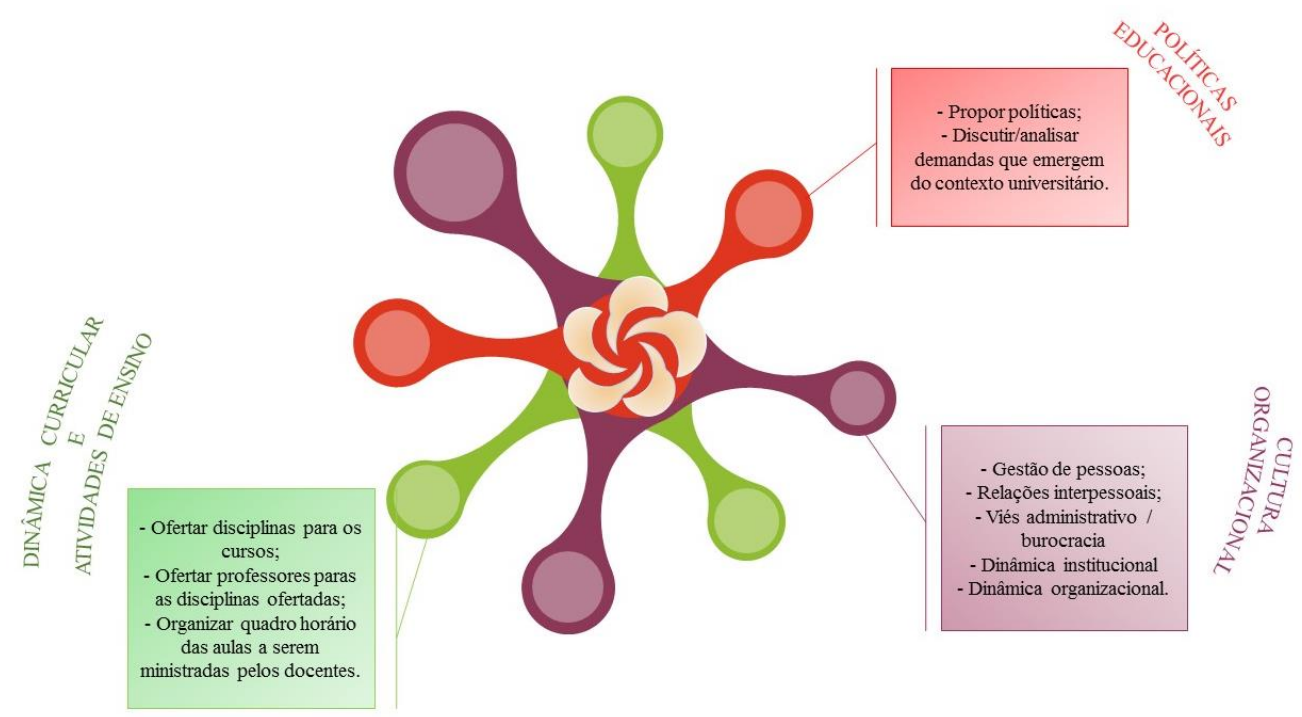

Fonte: Dewes (2017)

Por meio da narrativa dos professores gestores é possível identificarmos como essas dimensões vão se articulando, de tal modo que mesmo que se distinguem em alguns momentos, no seguinte se articulam, tornando a gestão dinâmica. Entendemos que o movimento de uma espiral elucida esse processo, pois movimentos de aproximação e distanciamento vão culminar em um único resultado: o processo de desenvolvimento da gestão. Ou seja, peguemos como exemplo a gestão de pessoas: é um elemento da dimensão cultura organizacional, com definições específicas, no entanto, se articula à oferta de disciplinas aos cursos, pois implica nos encargos didáticos dos professores, implica na organização dos horários das disciplinas e dos docentes, para que haja um equilíbrio entre a carga horária de trabalho de cada docente e que, também, todas as disciplinas tenham um docente responsável. Atrelado a isso, também aparecem os elementos relacionados às políticas educacionais, na maioria das vezes, caraterizados por políticas e programas governamentais que estabelecem novas exigências às IES. A própria contratação de mais profissionais depende de autorização do governo para ampliar o quadro de vagas.

Como acompanhamos nas narrativas dos professores gestores, essa articulação e interlocução das dimensões caracterizam a amplitude e a complexidade da gestão de um Departamento Didático, bem como a sua função dentro da estrutura de uma IES pública federal.

\section{REFERÊNCIAS}


BERGUE, S. T. Gestão estratégica de pessoas no setor público. São Paulo, SP: Atlas, 2014.

BOLZAN, D. P. V. Formação de professores: compartilhando e reconstruindo conhecimentos. Porto Alegre, RS: Mediação, 2002.

BOLZAN, D. P. V. Docência e Processos Formativos: estudantes e professores em contextos emergentes. Projeto de Pesquisa $n^{\circ}$ 042025, GAP/CE/UFSM, 2016.

CLANDININ, F. J. CONNELLY, F. M. Pesquisa Narrativa: experiências e história na pesquisa qualitativa. Uberlândia, MG: EDUFU, 2011.

COLOMBO, S. S. A gestão de pessoas nas instituições de ensino. In.: COLOMBO, S. S.; CARDIM, P. A. G. \& colaboradores. Nos Bastidores da Educação Brasileira: a gestão vista por dentro. Porto Alegre, RS: Artmed, 2010.

CUNHA, M. I. A indissociabilidade do ensino com a pesquisa e a extensão como referente da qualidade na universidade brasileira: um discurso em tensão. In.: CUNHA, M. I. (Org.). Qualidade da graduação: a relação entre ensino, pesquisa e extensão e o desenvolvimento profissional docente. Araraquara, SP: Junqueira\&Marin, 2012.

DEWES, A. Gestão universitária: departamentos didáticos e contextos emergentes da educação superior pública. 2017. 230f. Santa: UFSM, 2017. Monografia (especialização em Gestão Educacional). Centro de Educação, Universidade Federal de Santa Maria.

FREITAS, M. T. A. RAMOS, B. S. (Org.). Fazer pesquisa na abordagem históricocultural: metodologias em construção. Juiz de Fora, MG: Ed. UFJF, 2010.

MOROSINI, M. C. Educação Superior e Contextos Emergentes. Projeto de Pesquisa. PRONEX/FAPERGS/RIES. Porto Alegre, RS: PUC/RS, 2016.

SOUSA, A. M. C. Gestão acadêmica atual. In.: COLOMBO, Sonia S.; RODRIGUES, Gabriel M. Desafios da gestão universitária contemporânea. Porto Alegre, RS: Artmed, 2011.

TOFIK, D. S. A gestão acadêmica nas instituições de ensino superior. In.: COLOMBO, Sonia S. (Org.). Gestão universitária: os caminhos para a excelência. Porto Alegre, RS: Penso, 2013.

UNIVERSIDADE FEDERAL DE SANTA MARIA. Regimento Geral da Universidade Federal de Santa Maria. Santa Maria, RS: 2011. Disponível em:

http://site.ufsm.br/arquivos/uploaded/arquivos/7a09d209-53a6-49a7-90c7-b99c7d82c16b.pdf. Acesso em: 20 out. 2015.

VYGOTSKI, L. S. Pensamento e linguagem. São Paulo, SP: Martins Fontes, 1993.

VYGOTSKI, L. S. A formação social de mente. São Paulo, SP: Martins Fontes, 2007. 


\section{Como referenciar este artigo}

DEWES, Andiara.; BOLZAN, Doris P. V. Tempos e espaços da gestão universitária: compreendendo a gestão de departamentos didáticos. Revista on line de Política e Gestão Educacional, Araraquara, v. 22, n. 3, p. 961-977, set./dez. 2018. E-ISSN:1519-9029. DOI: 10.22633/rpge.v22i3.11308

Submetido em: $20 / 04 / 2018$

Aprovado em: 30/06/2018 